\title{
Diagnosing STEMI in the presence of paced rhythm: dispelling the myth of the 'uninterpretable paced ECG'
}

\author{
Apostolos Vrettos, ${ }^{1,2}$ Vasileios Panoulas ${ }^{2}$
}

${ }^{1}$ Cardiology, Buckinghamshire Healthcare NHS Trust, Amersham, UK

${ }^{2}$ Cardiology, Harefield Hospital, Harefield, UK

\section{Correspondence to} Dr Apostolos Vrettos; apostolos.vrettos@hotmail.com

Accepted 8 July 2021

\section{DESCRIPTION}

An 88-year-old woman presented to our hospital due to an 18-hour history of worsening central chest pain. She had a dual-chamber pacemaker due to second-degree Mobitz type II atrioventricular block implanted 10 years ago. Her risk factors included hypertension and hypercholesterolaemia. Her admission ECG showed a ventricular paced rhythm with ST changes consistent with ST-elevation myocardial infarction (STEMI) according to Smith-modified Sgarbossa criteria (SMSC) (figure 1), leading to activation of the primary percutaneous coronary intervention (pPCI) pathway. An urgent coronary angiogram showed a proximally occluded left anterior descending artery, and pPCI of the culprit vessel was performed, with restoration of Thrombolysis in Myocardial Infarction (TIMI) II flow (figure 2). A bedside echocardiogram showed akinetic anterior and anteroseptal walls with severely impaired left ventricular systolic function. The post-pPCI ECG showed paced rhythm with resolution of the ST-segment changes. Unfortunately, 2 days later she developed cardiogenic shock, suffered a cardiac arrest and died.
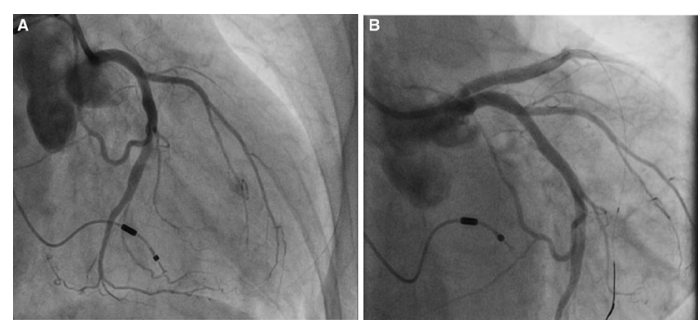

Figure 2 Coronary angiogram showing an occluded left anterior descending artery $(A)$ with restoration of flow following primary percutaneous coronary intervention (B).

It is believed that a left bundle branch block (LBBB) pattern on the ECG can complicate the electrocardiographic diagnosis of acute myocardial infarction (AMI) due to the presence of repolarisation abnormalities hiding ST-segment changes consistent with myocardial ischaemia. Right ventricular paced rhythm (RVPR) results in an intraventricular conduction delay similar to that seen with LBBB. As is the case with LBBB, it is a common misconception that one cannot identify STEMI in a patient with a ventricular paced rhythm.
Check for updates

(c) BMJ Publishing Group Limited 2021. No commercial re-use. See rights and permissions. Published by BMJ.

To cite: Vrettos $\mathrm{A}$, Panoulas V. BMJ Case Rep 2021:14:e242546 doi:10.1136/bcr-2021242546

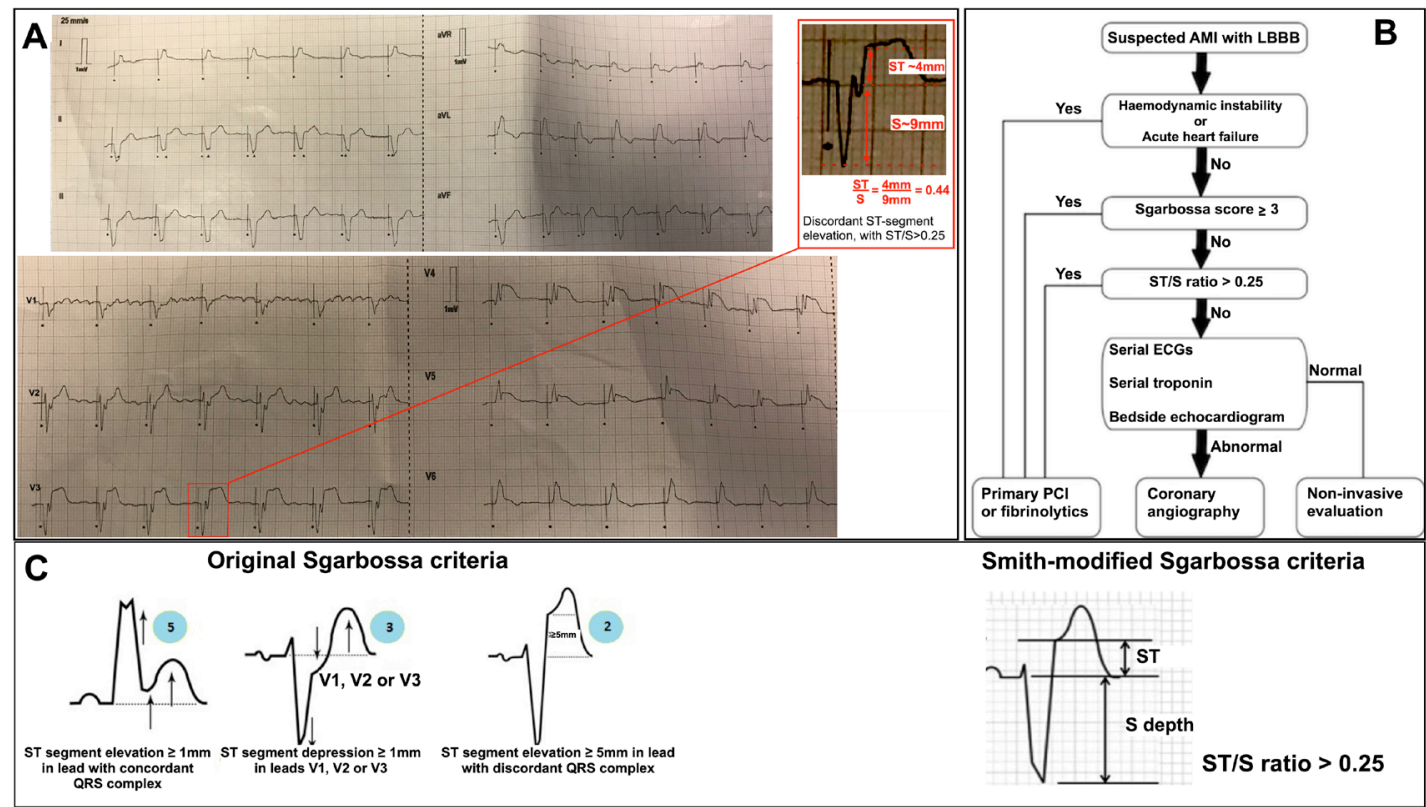

Figure 1 (A) Patient's ECG on arrival meeting the Smith-modified Sgarbossa criteria for STEMI. (B) The diagnostic algorithm proposed for diagnosing STEMI in RVPR/LBBB. (C) The original and the Smith-modified Sgarbossa criteria. AMI, acute myocardial infarction; LBBB, left bundle branch block; PCl, percutaneous coronary intervention; RVPR, right ventricular paced rhythm; STEMI, ST-elevation myocardial infarction. 


\section{Learning points}

- Right ventricular pacing with left bundle branch block (LBBB) morphology can complicate ECG interpretation in the diagnosis of acute myocardial infarction (AMI), but careful analysis of it is still important, as it can occasionally be diagnostic.

- The Smith-modified Sgarbossa criteria are significantly more sensitive than the original Sgarbossa criteria for the diagnosis of $\mathrm{AMI}$ in paced rhythm/LBBB.

- If a patient meets the Sgarbossa or Smith-modified Sgarbossa criteria in an appropriate clinical context, prompt cardiac catheterisation laboratory activation is appropriate.

The original Sgarbossa criteria (OSC) have traditionally been used to assist with the diagnosis of STEMI in patients with LBBB and RVPR, ${ }^{1}$ and are the following:

- Concordant ST-segment elevation $\geq 1 \mathrm{~mm}$ for leads with a predominantly positive QRS complex-score of 5 .

- Concordant ST-segment depression $\geq 1 \mathrm{~mm}$ in leads $\mathrm{V}_{1}, \mathrm{~V}_{2}$ or $\mathrm{V}_{3}$-score of 3 .

- Excessively discordant ST-segment elevation $\geq 5 \mathrm{~mm}$ in leads with negative QRS complexes-score of 2 .

A total score of $\geq 3$ suggests that the patient is having an AMI. However, although the specificity of the OSC is good, their sensitivity is low and cannot be applied to rule out an acute coronary event. Smith et $a l^{2}$ derived the SMSC using angiographic outcomes and defining excessively discordant ST elevation in proportion to the preceding $\mathrm{S}$-wave if greater than one-fourth its depth (ST/S ratio $>0.25)$, rather than using an absolute value $(\geq 5 \mathrm{~mm}$ ), proposing a modification to the OSC third criterion and the diagnostic algorithm (figure 1 ). ${ }^{2}$ A recent multicentre retrospective study showed that the SMSC are far more sensitive than the OSC for the diagnosis of AMI in the presence of RVPR (sensitivity of $81 \%$ vs $56 \%$ ) while maintaining high specificities (84\% vs $90 \%) .{ }^{3}$ The sensitivity of the SMSC is even higher if criterion 2 from the OSC is extended out to V1-V6 (instead of only V1-V3). ${ }^{3}$ These findings dispel the notion that it is not possible to diagnose AMI in patients with RVPR and LBBB, many of whom would be candidates for timely reperfusion therapy.

Contributors VP has collected the clinical information for this case and supervised the writting up of the case as the senior author. AV reviewed the literature and wrote the discussion part of this case. Both authors worked together to format the manuscript appropriately.

Funding The authors have not declared a specific grant for this research from any funding agency in the public, commercial or not-for-profit sectors.

Competing interests None declared.

Patient consent for publication Obtained.

Provenance and peer review Not commissioned; externally peer reviewed.

\section{REFERENCES}

1 Sgarbossa EB, Pinski SL, Gates KB, et al. Early electrocardiographic diagnosis of acute myocardial infarction in the presence of ventricular paced rhythm. GUSTO-I Investigators. Am J Cardiol 1996;77:423-4.

2 Smith SW, Dodd KW, Henry TD, et al. Diagnosis of ST-elevation myocardial infarction in the presence of left bundle branch block with the ST-elevation to s-wave ratio in a modified Sgarbossa rule. Ann Emerg Med 2012;60:766-76.

3 Dodd KW, Zvosec DL, Hart MA, et al. Electrocardiographic diagnosis of acute coronary occlusion myocardial infarction in ventricular paced rhythm using the modified Sgarbossa criteria. Ann Emerg Med 2021;S0196-0644:00249-3.

Copyright 2021 BMJ Publishing Group. All rights reserved. For permission to reuse any of this content visit

https://www.bmj.com/company/products-services/rights-and-licensing/permissions/

BMJ Case Report Fellows may re-use this article for personal use and teaching without any further permission.

Become a Fellow of BMJ Case Reports today and you can:

- Submit as many cases as you like

- Enjoy fast sympathetic peer review and rapid publication of accepted articles

- Access all the published articles

Re-use any of the published material for personal use and teaching without further permission

Customer Service

If you have any further queries about your subscription, please contact our customer services team on +44 (0) 2071111105 or via email at support@bmj.com.

Visit casereports.bmj.com for more articles like this and to become a Fellow 